\title{
Revisitando uma polêmica: as teses de Henri Pirenne sobre a Economia Medieval
}

\author{
José D'Assunção Barros \\ Professor-Adjunto da Universidade Federal Rural do Rio de Janeiro (UFRRJ) e Doutor em História pela \\ Universidade Federal Fluminense (UFF). \\ Endereço para contato: Rua Engenheiro Ernani Cotrim, 155 - Rio de Janeiro - RJ \\ CEP: 20510-260 - E-mail: jose.d.assun@globomail.com
}

Recebido em 25 de julho de 2014. Aceito em 21 de novembro de 2014.

\begin{abstract}
Resumo
Este artigo pretende analisar e discorrer sobre as clássicas teses do historiador belga Henry Pirenne sobre a formação e declínio da Idade Média, o desenvolvimento das cidades neste período e a reintensificação do comércio de longa distância, examinando em seguida todo o debate que se estabeleceu nas décadas seguintes em contraposição a algumas das propostas pirennianas para a compreensão do período medieval.
\end{abstract}

\section{Palavras-chave}

Pirenne; historiografia; debates medievalistas.

\begin{abstract}
This article aims to analyze and discuss the classic thésis of the belgian historian Henry Pirenne about the formation and decline of the Middle Ages, the development of cities in this period and intensification of long-distance trade, examining in the sequence the great debate that was established in the following decades about some of the proposals of Pirenne to understand the medieval period.
\end{abstract}

\section{Key-words}

Pirenne; historiography; medievalists debates. 


\section{Introdução}

A terceira década do século XX foi marcada por uma importante polêmica em torno da transição do mundo antigo para o ocidente medieval, do papel histórico do comércio e das cidades medievais, e da transição da medievalidade para um novo mundo que prenuncia a idade moderna. A polêmica teve como centro de gravidade algumas teses bastante instigantes propostas precisamente por Henri Pirenne. As teses de Pirenne sobre a transição da antiguidade à Idade Média, e sobre a interação entre o comércio e a Cidade Medieval a partir do século XI, causaram tanto impacto nas terceira e quarta décadas do século XX, que suscitaram inúmeras adesões de primeira hora e, particularmente nas décadas posteriores, muitas críticas provenientes de diversos lados. Algumas das contribuições de Pirenne com este complexo de teses sobre a Idade Média foram certamente duradouras. Podemos registrá-las em suas principais linhas, com o devido distanciamento permitido por um já longo desenvolvimento historiográfico que hoje permite enxergar com maior clareza as contribuições efetivas de Pirenne para os estudos medievais.

Em primeiro lugar, (1) não há dúvidas de que foi primordial para a historiografia posterior o destaque atribuído por Pirenne à função econômica da Cidade Medieval, em contraste com a maior parte da historiografia de sua época, que então se concentrava apenas na análise institucional do fenômeno urbano. Em segundo lugar, (2) Pirenne foi um dos primeiros historiadores a valorizar, para o período medieval, o papel do mercado como elemento de fixação urbana. Nesta direção, seu trabalho rivaliza com o de Max Weber (1958), que, embora não tenha se dedicado apenas ao estudo das cidades medievais, também possui uma contribuição importante neste âmbito temático. Por fim, (3) foi particularmente importante a análise elaborada por Pirenne acerca do papel dos grandes mercadores na vida urbana medieval e na transformação do mundo feudal, além do historiador belga ter demonstrado a importância dos próprios meios rurais para o fornecimento de um contingente importante de indivíduos que se integraram à dinâmica comercial. Por outro lado, é preciso reconhecer que, para além destas contribuições indubitavelmente significativas, algumas das teses centrais de Pirenne não resistiram às críticas e investigações historiográficas encaminhadas nas décadas seguintes. Resumiremos a seguir o conjunto de teses de Pirenne, para pontuar a seguir outras indicações autorais, inclusive as mais críticas, relativas a esta grande polêmica da primeira metade do século.

\section{As teses de Pirenne sobre a Idade Média, na década de 1920}

As instigantes idéias de Pirenne ganharam projeção na década de 1920 a partir de duas obras principais, e também em alguns artigos elaborados e publicados na mesma época. De um lado, Pirenne apresentou suas impactantes teses sobre a renovação do comércio medieval no célebre artigo denominado Maomé e Carlos Magno (PIRENNE, 1922, p.77-86). Este artigo também rediscute a fronteira historiográfica entre o mundo antigo e a Idade Média, ao colocar como centro do problema histórico a 
ascensão do Islamismo e a formação do Império Carolíngio. Mais tarde, em 1936, Pirenne incorporou as idéias apresentadas neste artigo a um tratado mais amplo, denominado História Econômica e Social da Idade Média (PIRENNE, 1982), e na própria década de 1920 continuou produzindo artigos dentro do mesmo circuito de idéias (PIRENNE, 1923, p.223-235). A segunda obra que polarizou a polêmica em torno das idéias de Pirenne foi um pequeno mas marcante livro intitulado As Cidades na Idade Média, publicado em inglês em 1925 (PIRENNE, 1962) ${ }^{1}$. As propostas desta obra para uma compreensão das cidades medievais remontam, na verdade, a alguns artigos anteriores, que Pirenne publicara ainda no final do século XIX (PIRENNE, 1898, p.111122). Além disto, posteriormente o historiador belga acrescentou a seu estudo original sobre a Cidade Medieval alguns artigos mais específicos, publicados nos primeiros números da Revista de História Econômica e da Revista dos Annales (PIRENNE, 1905, p.18).

Podemos resumir a seguir o primeiro circuito de questões (sobre a renovação do comércio medieval), que na verdade engloba o segundo (sobre a origem e natureza das cidades medievais). A idéia central é a de que, de algum modo, Maomé e Carlos Magno constituem as duas faces de uma mesma moeda no que se refere aos destinos da história da Europa Ocidental. A expansão islâmica teria neste caso condicionado diretamente o padrão que se inicia com o Império Carolíngio no Ocidente, uma vez que o modelo de comércio, as suas rotas e os seus agentes sofreram mudanças radicais após o controle muçulmano sobre determinadas áreas do Mediterrâneo. Esta retração comercial trouxe consigo uma imediata retração urbana, o que já nos introduz no âmago do segundo circuito de questões evocadas pelas teses de Pirenne. Podemos registrar as próprias palavras do historiador belga no seu tratado sobre a História Econômica e Social da Idade Média:

\footnotetext{
"Quando a invasão islâmica fechou os portos do mar Tirrênio ... a atividade municipal rapidamente se extinguiu. Salvo no sul da Itália e em Veneza, onde foi mantida graças ao comércio com Bizâncio, ela desapareceu em toda a parte. As cidades continuaram a existir, mas perderam sua população de artesãos e mercadores e, com eles, tudo o que sobrevivera da organização municipal do Império Romano" (PIRENNE, 1936, p.40)
}

Diante deste novo momento histórico, o "Estado" (expressão utilizada neste caso pelo próprio Pirenne) teve de se adaptar a uma realidade que já não contaria mais com a mesma dinâmica comercial e com a mesma rede urbana. Para este aspecto particular, pode-se retomar algumas colocações do historiador belga:

"Do ponto de vista econômico, a instituição mais notável e característica
dessa civilização foi o grande Estado. Sua origem, claro, é muito antiga, e é
fácil comprovar-lhe a filiação a um passado muito remoto ... [...] A novidade
[porém] foi a maneira como ele funcionou a partir do desaparecimento do
comércio e das cidades. Enquanto o comércio foi capaz de transportar-lhe os
produtos e as cidades de fornecer-lhe um mercado, o grande Estado
comandou e conseqüentemente lucrou coma venda regular fora de suas 1 esta obra, publicada em francês em 1927, pela editora Lamertin, acrescenta textos ao livro publicado em
inglês em 1925 .

Econ. e Desenv., Santa Maria, vol. 26, n.2, p. 43 - 55, jul. - dez. 2014 
fronteiras... mas agora cessava de assim agir porque não havia mais mercadores nem citadinos... agora que todos viviam de sua própria terra, ninguém se dava ao trabalho de comprar alimentos no exterior... Assim, cada Estado se dedicou ao tipo de economia que tem sido descrita, com grande inexatidão, como 'economia fechada na grande propriedade' e que foi, na realidade, simplesmente uma economia sem mercados" (PIRENNE, 1936, p.8).

\section{As cidades na leitura de Pirenne sobre as transformações na economia medieval}

As teses de Henri Pirenne sobre as modificações no âmbito comercial, a partir das mudanças políticas e econômicas que ocorriam com a expansão islâmica e com a consolidação do mundo carolíngio, levaram o historiador belga a repensar mais especificamente a história e o papel das cidades no mundo medieval. Estas proposições aparecem colocadas com muita clareza no livro As Cidades na Idade Média (PIRENNE, 1962), publicado em 1925. Podemos sintetizá-las esquematicamente:

- Síntese das proposições de Pirenne contidas em As Cidades da Idade Média (1925):

1. Existiria uma continuidade comercial em torno do Mediterrâneo até o século VIII, abarcando Antigüidade e Idade Média pré-carolíngia. (capítulo I)

2. No período carolíngio ocorre a ruptura: os muçulmanos fecham o Mediterrâneo. Com isto, o Império Carolíngio tornar-se-á terrestre, essencialmente agrícola, e com um comércio em declínio. Este aspecto da sociedade carolíngia corresponde à outra face do surgimento do mundo império islâmico. (capítulo II)

3. As invasões normandas, no final do século IX, reforçam a ruptura. (capítulo III)

4. No que concerne à Cidade Medieval, Pirenne a conceitua em oposição aos núcleos préurbanos (burgos fortificados) e às persistências das civitas romanas, agora transformadas em meras sedes episcopais (para Pirenne, os atributos imprescindíveis da cidade são uma população burguesa e uma organização municipal). (capítulo III)

5. No século XI, o "Renascimento Comercial" - produzido a partir de uma "excitação externa" a partir dos contactos de Veneza e Flandres com o exterior - restabelece o Renascimento Urbano. (capítulo IV)

6. Os mercadores, atores neste conjunto de mutações, são fundamentalmente indivíduos errantes e desenraizados. (capítulo V)

7. A partir destas colocações, Pirenne generaliza um modelo de formação da Cidade Medieval: em decorrência do "Renascimento Comercial", as cidades formam-se em torno de núcleos pré-urbanos que proporcionam segurança. (capítulo VI)

8. As instituições urbanas são edificadas diretamente em torno dos interesses da burguesia mercantil. (Capítulo VII). 
Estas teses, apresentadas por Henri Pirenne com uma escrita fluente e argumentativa, provocaram de imediato grande entusiasmo, mas também críticas (ainda na sua própria época, mas sobretudo nas décadas subsequentes). Com o tempo, as críticas foram superando claramente o entusiasmo que as teses de Pirenne haviam despertado em um momento inicial. Estas críticas também podem ser indicadas esquematicamente. $\mathrm{O}$ nome de alguns autores entre parênteses é meramente exemplificativo, e objetiva apontar obras que poderão ser consultadas com relação às críticas encaminhadas.

\section{- Principais críticas às teses de Pirenne:}

1. Críticas às teses do fechamento do mediterrâneo e do "hiato urbano" (Ganshof, R. S. López)

2. Críticas a um conceito demasiado estreito de cidade, que teria sido utilizado por Pirenne (Lewis Mumford)

3. Críticas à desconsideração do peso desenvolvimento da economia rural sobre o desenvolvimento urbano (Guy Fourquin)

4. Críticas à generalização de um modelo único de "mercador-banqueiro": o desenraizado e vindo de longe (Fourquin, Le Goff)

5. Críticas à generalização de um modelo único de formação urbana para o período medieval (desmentida por uma série de estudos de caso que mostram a variedade do fenômeno urbano medieval, sobretudo a partir da década de 50).

Henri Pirenne não se limitou, naturalmente, às suas primeiras formulações sobre o desenvolvimento comercial e urbano medieval. Em um artigo datado de 1929, dedicado a uma avaliação mais específica das cidades holandesas, o historiador belga acrescenta, às suas teses sobre o 'fechamento do Mediterrâneo', novos desdobramentos (PIRENNE, 1928, p.18). Por um lado, (1) a irrupção do Islã teria tido uma repercussão imediata na Holanda; e, por outro lado, (2) a descida dos nórdicos sobre a Inglaterra e o continente europeu no século IX constituíram conseqüências posteriores do mesmo fenômeno. Na própria época de Pirenne, já começaram a surgir algumas críticas importantes em relação ao circuito de proposições exposto pelo historiador belga no livro As Cidades da Idade Média (1925). Norman Baynes, por exemplo, encaminhou um bem articulado conjunto de críticas num periódico importante ainda naquela década (BAYNES, 1929, p.224-235). Antes dele, outro historiador - chamado Petrusevski - já havia feito severas críticas às proposições de Pirenne. Em 1928 ele apresentou um conjunto de proposições bastante antagônico em relação às teses de Pirenne (PETRUSEVSKI, 1928, p.468-490). $\mathrm{Na}$ verdade, o historiador chega a defender uma tese radicalmente oposta às proposições de 'declínio comercial' tal como haviam sido formuladas por Pirenne - chegando a se 
mostrar até mesmo unilateral na direção contrária. Podemos adaptar aqui um comentário bastante pertinente de Norbert Elias em O Processo Civilizador (1939):

\begin{abstract}
“À tese estática, segundo a qual a 'economia de troca' e a 'economia monetária' não expressaram a direção de um processo histórico gradual, mas dois estados físicos separados, sucessivos e irreconciliáveis da sociedade, Petrusevski opôs a tese de que jamais existiu essa tal 'economia de troca"' (ELIAS, 1994, p.279).
\end{abstract}

Ou, para citar o próprio Petrusevski (1928, p.488):

\begin{abstract}
"Não queremos discutir aqui em detalhes o fato de que, como demonstrou Max Weber, a economia de troca constituiu uma dessas utopias eruditas que não só não existem e nunca existiram na realidade, mas que, ao contrário de outras ... que são também generalizações utopistas devido ao seu caráter lógico, jamais podem ter qualquer aplicação à sociedade concreta" (PETRUSEVSKI, 1928, p.488)
\end{abstract}

Mais adiante, Petrusevski demarca seu ponto de vista em oposição à tese de que o 'feudalismo' e a 'economia de troca' foram duas esferas, ou patamares, a última correspondendo à infra-estrutura que produziu e causou a primeira. Para Petrusevski, ao contrário, os dois fenômenos nada têm a ver entre si, correspondendo isto a "idéias que se chocam inteiramente com o fato histórico, tal como o de subordinação do feudalismo à economia de troca ou sua incompatibilidade com uma organização estatal abrangente" (PETRUSEVSKI, 1928, p.488). Outros historiadores, nesta mesma grande polêmica instigada por Henri Pirenne, empenharam-se em identificar aspectos que haviam sido negligenciados pelo historiador belga na sua generalização da história comercial e urbana do ocidente medieval. O historiador russo Rostovtzeff (ROSTOVTZEFF. 1930, p.197), por exemplo, chama atenção para um aspecto importante que havia sido desprezado por Pirenne na sua análise das transformações econômicas na Alta Idade Média: as alterações do gosto e suas implicações comerciais. De igual maneira, surgiram os questionamentos acerca dos fatores que deveriam ser considerados prioritariamente com relação à passagem para um modelo econômico mais fechado na Alta Idade Média. H. Moss (1936), por exemplo, critica nas teses de Henri Pirenne a negligência com relação a fatores de maior duração, e interpreta a "economia de casa fechada" da Europa Ocidental nos anos 800 como "diretamente provocada pelo colapso do governo romano, das comunicações e do comércio" (MOSS, 1936, p.209-216).

\title{
As críticas a Pirenne nas décadas seguintes
}

Nas décadas posteriores aos anos 1920 foram cada vez mais se estabelecendo críticas bastante consistentes a algumas das proposições de Henri Pirenne, e particularmente em relação ao questionamento da visão do mundo medieval como uma "economia de casa fechada" - o que, aliás, representava uma visão historiográfica bem típica das primeiras décadas do século $\mathrm{XX}$, e que era compartilhada até então por 
diversos historiadores. A partir de fins da década de 1940 esta visão foi sendo relativizada cada vez mais, e naturalmente isto contribuiu para que se acelerassem as críticas a certos pontos colocados por Pirenne em suas formulações. Podemos dar dois exemplos entre outros tantos que seriam possíveis. Em um artigo datado de 1938, François Ganshof discute muito objetivamente a afirmação de Pirenne de que o comércio teria decaído drasticamente no Ocidente após a invasão sarracena (GANSHOF, 1938, p.28-37). Críticas relacionadas à mesma questão são desenvolvidas em um artigo da década de 1940 por Roberto Sabatino López (LÓPEZ, 1943, p.14-38). Posteriormente, ainda no campo da História Econômica, as críticas dirigidas às formulações de Pirenne foram se tornando cada vez mais sistemáticas. Podemos dar como exemplo uma sequência de críticas elaboradas por Guy Fourquin (1969) em relação às teses de Pirenne sobre o desenvolvimento econômico e urbano medieval (FOURQUIN, 1991, p.239-265), que podem ser resumidas adequadamente em três grupos fundamentais.

(1) O modelo proposto por Pirenne para a revitalização urbana a partir do comércio das cidades de Flandres, e a sua descrição do modelo de crescimento urbano daí resultante, não pode ser generalizado para a maior parte da Europa Medieval. A este respeito, Guy Fourquin avalia objetivamente o mapa urbano da Idade Média central:

\footnotetext{
"Este quadro é indiscutivelmente válido para a região flamenga que Pirenne tomou para base de sua teoria, ainda que alguns portus sejam mais antigos, datando dos tempos carolíngios ou pós-carolíngios. Com efeito, por volta do ano 1000, havia poucas cidades nesta região. (...) o quadro esboçado por Pirenne é igualmente válido para as cidades — forçosamente novas — dos países novos, como as cidades hanseáticas da Alemanha. Mas Pirenne, e mais ainda os seus discípulos, pretenderam alargar a sua aplicação a todo o Ocidente, por exemplo, a toda a parte norte da França (Vercauteren) ou a Inglaterra" (FOURQUIN, 1991, p.240).
}

(2) Nem sempre, considerando as várias regiões da Europa, teria ocorrido o tal "hiato urbano" proposto por Pirenne. Assim, segundo Fourquin, "a continuidade urbana encontra-se quase sempre provada, mesmo na Flandres (Arras, Saint-Omer, Gand), desde a época carolíngia, e por vezes até desde os tempos merovíngios (como no vale do Mosa)" (1991, p.240).

(3) Para Fourquin, o comércio desenvolve-se com a expansão agrícola e populacional, situação que Pirenne desconsidera.

(4) Por fim, Pirenne teria ignorado outros tipos de cidade, igualmente presentes na medievalidade européia: cidades com dominância do artesanato; cidades semi-rurais (com mercadores e artesãos cultivando o campo). Fourquin encerra seu bloco de críticas com uma indagação: "Mas, vamos um pouco mais longe. Terá sido realmente a economia a desempenhar o primeiro papel em todas as cidades?" (1991, p.243). 
As críticas às propostas de Pirenne para a origem das cidades medievais também estiveram amplamente representadas nas décadas posteriores. De um lado, estas críticas partem da idéia de que não é possível reduzir o surgimento das novas cidades, e a revitalização das antigas, meramente a desdobramentos comerciais ou a aspectos derivados do âmbito econômico. Os historiadores da segunda metade do século XX tenderam a focar, para além da história econômica, aspectos diversos relacionados à religiosidade, às mentalidades, à cultura, ou a história social de maneira geral. Podemos dar como exemplo as críticas de Lewis Mumford (1961) às teses de Pirenne sobre a origem das cidades medievais, que são basicamente de duas ordens (MUMFORD, 1991, p.279). Em primeiro lugar, ele defende a idéia de que a origem da cidade medieval esteve associada à necessidade de uma nova forma de segurança, necessidade que foi atendida pela cidade-murada. Foi a revivescência da cidade protegida que assegurou a retomada comercial, e não o contrário (MUMFORD, 1991, p.280). Em segundo lugar, critica a definição estreita de cidade abordada por Pirenne. "Todo esse fenômeno foi mal interpretado por Pirenne, porque ele recusava o título de cidade a uma comunidade urbana que não incentivava o comércio a longa distância, nem abrigava uma grande classe média mercantil - uma definição inteiramente arbitrária" (MUMFORD, 1991, p.279).

\section{Um balanço sobre a contribuição de Pirenne, diante das críticas suscitadas.}

Conforme vimos, algumas das principais teses de Henri Pirenne sobre a Idade Média não resistiram ao desenvolvimento posterior da historiografia. Boa parte das suas generalizações não resistiu à complexidade histórica encontrada pelas gerações seguintes de medievalistas, e diversas formulações conceituais tornaram-se nãooperacionais ou inadequadas (como a noção de "renascimento comercial", por exemplo, ou a de "fechamento do Mediterrâneo"). Tampouco resistiu ao tempo a busca pirenniana de um modelo único de "ressurgimento urbano medieval", do mesmo modo que inúmeras outras explicações históricas totalizantes e unilaterais, em diversos autores da primeira metade do século XX, tenderam a serem revistas por uma historiografia que iluminou mais a diversidade e complexidade de situações históricas do que a homogeneidade de modelos unificadores ${ }^{2}$. Devemos nos perguntar, nestes momentos finais, sobre as razões para o inquestionável sucesso de Henri Pirenne em permanecer na galeria dos historiadores mais lembrados do último século. Sobre isto, de fato, ainda há algo mais a dizer.

Quando pensamos no fato de que o tempo revelou a inadequação das respostas mais específicas dadas por Pirenne às grandes questões sobre a Idade Média, não

\footnotetext{
${ }^{2}$ De todo modo, vale lembrar que, apesar da rejeição das grandes generalizações de Pirenne para o período medieval, diversas contribuições do historiador belga para a história da Idade Média foram assimiladas. J. F. Verbruggen lembra que, "depois do artigo de Pirenne sobre 'As cidades flamengas antes do XII ${ }^{\circ}$ século', o conceito de castrum passou a ser o termo técnico para designar os castelos do condado de Flandres" (VERBRUGGEN, 1950, p.147-155).
} 
podemos nos esquecer que suas maiores lições ao mundo historiográfico se referiram precisamente à sua habilidade de propor novos problemas - em uma palavra, à sua capacidade de olhar para a história de maneira problematizada. O importante não é definir de uma vez por todas se a Idade Média começa no século VII com a ascensão do Islamismo e com uma nova configuração da Europa, mas sim entender, com Pirenne, que são os problemas propostos que redefinem as fronteiras sempre móveis entre os períodos históricos. Pirenne mostrou que havia uma nova historiografia a ser escrita: não se tratava apenas de contar os fatos ou de descrever sociedades historicamente localizadas; era preciso pensar novas conexões de modo a enxergar a história de novas maneiras. Conectar a ascensão islâmica e a interiorização carolíngia, ou o crescimento rural e a reintensificação do comércio medieval, são exemplos pirennianos de que as sequências históricas de fatos ou processos não falam por si mesmas, e que, ao contrário, adquirem novos sentidos quando contrapostas umas às outras no interior de uma análise historiográfica problematizada.

Se considerarmos que Henri Pirenne ofereceu aos seus contemporâneos novas formas de enxergar a história, novas perguntas a serem feitas e novos problemas a serem colocados, tornam-se menos importantes as respostas específicas encontradas pelo historiador belga a esta ou àquela questão. Não é de se estranhar que os jovens historiadores que iriam formar o movimento dos Annales - tais como Lucien Febvre, Marc Bloch e depois Braudel - tenham situado Pirenne na sua galeria de precursores. A nova historiografia que iria cunhar a noção de História-Problema não poderia deixar de reverenciar um historiador que surpreendeu a sua época com novos problemas. Além disto, Henri Pirenne também fora um dos historiadores que mais contribuíram para alargar definitivamente o horizonte historiográfico predominante para além dos limites mais estreitos da historiografia política tradicional. Ao trazer a Economia para o centro do cenário historiográfico, Pirenne integrava-se a uma nova tendência que definitivamente gestava algo de novo, e que teria no movimento dos Annales e nas realizações historiográficas do materialismo histórico contemporâneo duas de suas maiores expressões.

Estas duas realizações - a problematização da história e a ampliação dos horizontes historiográficos - não implicaram, nas obras de Henri Pirenne, em uma perda da habilidade narrativa do historiador. Henri Pirenne foi também um mestre da escrita historiográfica, e essa lição ainda ressoa nos dias de hoje. Quando se verifica uma certa perda de estilo historiográfico em muitos dos historiadores econômicos das últimas sete décadas, vem à mente a sua contrapartida: Henri Pirenne, um historiador econômico que não abriu mão de um estilo fluente, sedutor, ou mesmo literário - capaz de discutir as relações econômicas ao mesmo tempo em que nos fazia seguir as trajetórias de vida de mercadores que deixaram seus vestígios nas fontes, ou de estender o olhar para a amplidão do Mediterrâneo como mais tarde o faria Fernando Braudel, entretecendo uma história na qual as próprias cidades se transformavam em grandes personagens de um enredo maior. Pirenne, seguramente, é mais um elo na grande cadeia de historiadores que foram também grandes escritores. Esta lição, em seus diversos livros e artigos, continua sendo uma contribuição notável à comunidade sempre renovada de historiadores.

Econ. e Desenv., Santa Maria, vol. 26, n.2, p. 43 - 55, jul. - dez. 2014 


\section{A contribuição de Pirenne para uma história global e comparada}

Há algo mais a dizer sobre as grandes generalizações de Pirenne. Na verdade, estas encobrem outro aspecto importante: a motivação de escrever uma história global, não relacionada a apenas um país ou a uma localidade específica. Conforme acentuamos antes, houve um sutil deslocamento de um Pirenne historiador nacional, especificamente belga - o mesmo que estava particularmente preocupado com As Origens do estado Belga (1906) ou com As cidades flamengas do século XII (1905) - a um Pirenne historiador da Europa, que introduz as primeiras grandes preocupações em favor de uma nova modalidade historiográfica, a História Comparada, ao lado de outros autores que logo lhe seguiriam, entre os quais o próprio Marc Bloch. Uma sinalização pioneira para uma perspectiva comparatista, na alvorada de uma historiografia que logo reservaria um lugar de honra para a modalidade da História Comparada, pode ser indicada como outra das grandes contribuições de Pirenne que o fariam sobreviver às críticas mais implacáveis desfechadas contra as suas teses específicas sobre a Idade Média.

Como ocorreu a vários outros historiadores que vivenciaram o período das guerras mundiais, o que despertou em Pirenne o impulso para o olhar comparado foi a urgência de erguer a visão historiográfica para além dos limites nacionais - que de certo modo haviam resultado não apenas no nacionalismo historiográfico, como também no nacionalismo belicista. O insight nesta direção ocorre a Pirenne no período em que esteve preso pelos alemães nos anos finais da Primeira Grande Guerra, entre 1916 e $1918^{3}$. Este período de aprisionamento no contexto da guerra pode ser mesmo indicado como um divisor d águas na historiografia de Pirenne, ou como o doloroso momento em que Pirenne se vê compelido a deixar de ser um historiador belga para se tornar um historiador para o mundo. A reflexão sobre os horrores daquela grande guerra, para a qual os europeus haviam sido conduzidos sob a égide dos nacionalismos exacerbados, levariam Henri Pirenne ao projeto de escrever uma História da Europa, das invasões ao século XVI (1936) - quem sabe o desesperado anseio de encontrar as origens do esfacelamento de uma unidade maior, e ainda, talvez, o angustiante desejo de reencontrar esta unidade européia no futuro. Estas inquietações também foram acompanhadas de uma reflexão mais específica sobre as potencialidades do Método Comparativo em História, que finalmente se concretizou em uma conferência em 1923, um ano antes de Marc Bloch se entregar à tarefa de redigir Os Reis Taumaturgos (1924), a primeira "história comparada-problema". De igual maneira, os artigos de Pirenne que ressurgem com força total na década de 1920 - após um significativo silêncio que pode ser comprovado com o exame cronológico de sua produção bibliográfica - indicam doravante questões mais gerais, que dizem respeito a toda a Europa, e não apenas a Bélgica.

\footnotetext{
${ }^{3}$ Sobre esta passagem de Pirenne pelo período da Primeira Guerra, ver VIOLANTE, 1997 e LYON, 1974.
} 


\section{Considerações finais}

Nos dias de hoje, devemos nos perguntar se as grandes generalizações de Pirenne sobre a Idade Média também não encobriam este mesmo anseio de pensar a Europa em uma perspectiva mais ampla. Ao desconsiderar as realidades locais - que depois tantas vezes lhes seriam cobradas pelos seus maiores críticos -, ou ao tentar subsumi-las em uma generalização mais ampla, não estaria se expressando em Pirenne a inquietante busca de pensar a História da Europa como um grande movimento, à maneira de preparar-se para pensá-la como um grande povo? Nestes tempos recentes, entre as últimas décadas do século $\mathrm{XX}$ e as primeiras do século XXI, quando convivemos com os esforços dos diversos países europeus em constituir uma difícil unidade européia, podemos ser mais condescendentes em relação às grandes generalizações de Pirenne sobre as origens da Idade Média e sobre a história das cidades e do comércio internacional. Não é difícil compreender que a incansável busca de uma humanidade comum, contra os diversos contextos contemporâneos que a fragmentam, tem sido talvez o principal aspecto que tem permitido a inabalável persistência de Henri Pirenne na galeria dos grandes historiadores de todos os tempos. Se ao começarmos a analisar a contribuição historiográfica de Henri Pirenne começamos por percebê-lo como um historiador belga, ao avançarmos nesta mesma análise não há como deixar de percebê-lo, em seguida, como um historiador europeu. Por fim, Henri Pirenne termina por se afirmar em uma dimensão ainda mais ampla, a de um historiador para o mundo.

\section{REFERÊNCIAS}

\section{Obras de Henri Pirenne.}

PIRENNE, Henri. 1895. Origine des constitutions urbaines au Moyen Age. Revue Historique, tit. LVII. Paris, p.52-ss.

PIRENNE, Henri. 1898. Villes marchés et marchands au Moyen Age. Revue Historique. t.LXVII, Paris, p.111-122.

PIRENNE, Henri. 1900-1931. Histoire de Belgique. Bruxelas: Lamertin, sete volumes.

PIRENNE, Henri. 1905. Les villes flamandes avant le XII siècles. Annales d'Est et du Nord. tit.I, Paris, p.18-ss.

PIRENNE, Henri. 1906.Les origines de l'état belgue. Bruxelles: Desoer.

PIRENNE, Henri. 1910. Les anciennes democraties des Pays-Bas. Paris: Flammarion.

PIRENNE, Henri. 1922. Mahomet et Charlemagne. Revue belgue de philologie et d'histoire. $\mathrm{n}^{\circ} 1$, p.77-86.

PIRENNE, Henri. 1923. Un contraste économique : merovingians et carolingians. Revue belgue de philologie et d'histoire. $\mathrm{n}^{\circ} 2$, p.223-235.

PIRENNE, Henri. 1923. "De La méthode comparative en histoire" In: DES MAREZ, G. e GANSHOF, F-L (orgs). Compte-rendu du V Congrès des Sciences Historiques. Ghent: Weissenbrusch, p.19-32. 
PIRENNE, Henri. 1925. Medieval Cities: Their Origins and the Revival of Trade. Princeton: Princeton University Press.

PIRENNE, Henri. 1962. As Cidades na Idade Média. Lisboa: Europa-América [original: 1927].

PIRENNE, Henri, 1929. The Place of the Netherlands. Economic History Review, II, ${ }^{\circ}$ 2, p.20-40.

PIRENNE, Henri. 1930. Les villes et les intitutions urbaines, 2 vol. Paris / Bruxelles: Felix.

PIRENNE, Henri. 1933. Histoire Économique et sociale Du moyen âge. Vol VIII In: GLOTZ, Gustav (org), Histoire Générale. Paris: Gustav Glotz.

PIRENNE, Henri. 1936. Histoire de l'Europe - des invasions aux XVI siècle. Bruxelles: Neuchâtel.

PIRENNE, Henri. 1936. Economic and Social History of Medieval Europe. London: Trubner.

PIRENNE, Henri. 1992. Mahomet e Charlemagne. Paris: Quadrige [original: 1937].

PIRENNE, Henri. 1951. Histoire Économique de l'occident medievale. Brugues: Coornaert.

\section{Bibliografia de apoio:}

BACHRACH, B.S. 1998. "Pirenne and Charlemagne" In: MURRAY, A.C. (org), After Rome's Fall. Narrators and Sources of Early Medieval History. Toronto: University of Toronto Press, p.214-231.

BLOCH, Marc. 1993. Os Reis Taumaturgos. São Paulo: Companhia das Letras [original: 1924].

BLOCH, Marc. 1928. "Pour une histoire comparée dês sociétés européenes" in Revue de Synthèse Historique. Tome XLVI. Paris: La Renaissance du Livre. p.15-50.

BLOCH, Marc. 1930. "Comparaison” In Bulletin du Centre Internacional de Synthèse, n 9, Paris: jun/1930.

BLOCH, Marc. 2001. Apologia da História. Rio de Janeiro: Zahar [original: 1941-42].

BROWN, E. A. R. 1976. Henri Pirenne: a Biographical and Intellectual Study. History and Theory. $15, \mathrm{n}^{\circ} 1, \mathrm{p} .66-76$.

DESPY, G. e VERHULST, A. (orgs.). 1986. La fortune historiographique des thèses d'Henri Pirenne. Archives et Bibliothèques de Belgique. $\mathrm{n}^{\circ}$ 28. Bruxelles.

FOURQUIN, Guy. 1991. "As cidades e o setor secundário" In História Econômica do Ocidente Medieval, Lisboa: Edições 70, p.239-265 [original: 1969].

GANSHOF, François. 1936-a. Henri Pirenne: le mâitre, l'historien. Bruxelas: Editions du Flambeau.

GANSHOF, François. 1936-b. Henri Pirenne and Economic History. Economic History Review. Vol.6, p.179-185.

GANSHOF, François. 1938. Note sur les ports de Provence du VIII au X siècle. Revue Historique, CLXXXIII, p.28-37. 
GENICOT, Leopold. 1993. "Henri Pirenne" In: BURGUIÈRE, André. Enciclopédia das Ciências Históricas. Rio de Janeiro, Imago, p.597-599.

LAURENT, Henri. 1932. Les travaux de M. Pirenne sur la fin du monde antique et les débuts du Moyen Age. Byzantion. Revueinternationale des études byzantines, t. 7, p. 495-509.

LYON, B. Henri Pirenne. 1974. A Biographical and Intellectual Study. Gand: StoryScientia.

LYON, B. 1960. L'œuvre de Henri Pirenne après vingt-cinq ans, Le Moyen Age, n66, p.437-493.

ESPINAS, G. 1946. Les origines du patriciat urbain. Henri Pirenne s'est-il trompé?. Annales ESC, vol.1, n², p.143-153.

LE GOFF, Jacques. 1992. O Apogeu da Cidade Medieval. São Paulo: Martins Fontes [original: 1980].

LÓPEZ, Roberto Sabatino. 1943. Mohammed and Charlemagne: a Revision, Speculum XVIII, p.14-38.

MOSS, H. St. L. B. 1936. The Economic Consequences of the Barbarian Invasions. Economic History Review, VII, p.209-216.

MUMFORD, Lewis. 1991. A Cidade na História. São Paulo: Martins Fontes [original: 1965].

PETRUSEVSKI, D. M. 1928. Strittige Fragen der mittelalterlichen Verfassungs und Wirtschaftsgeschichte. Zeitschrift für die gesamte Staatswissenschaft, v.85. Tübingen, p.468-490.

ROSTOVTZEFF, Michael. 1930. The Decay of the Ancient World and its economic explanations. Economic History Review, n², p.197-ss.

VERBRUGGEN, J. F. 1950. Notes sur le sens des mots castrum, castellum, et quelques autres expressions qui désignent dês fortifications. Revue belge de philologie et d'histoire. vol.28, n¹, p.147-155.

VIOLANTE, Cinzio. 1997.La fine della «grande illusione». Uno storico europeo tra guerra e dopoguerra, Henri Pirenne (1914-1923). Per una rilettura della Histoire de l'Europe, Bologne: Instituto Trentino di Cultura.

WEBER, Max. 1958. The City. New York: Macmillan [original: 1925]. 